\title{
(2) OPEN ACCESS \\ PROSPECT guideline for hallux valgus repair surgery: a systematic review and procedure-specific postoperative pain management recommendations
}

\author{
Katarzyna Korwin-Kochanowska, ${ }^{1}$ Arnaud Potié, ${ }^{2}$ Kariem El-Boghdadly @ (๑) ${ }^{3}$ \\ Narinder Rawal, ${ }^{4}$ Girish Joshi, ${ }^{5}$ Eric Albrecht 0 , ${ }^{2}$ the PROSPECT/ESRA Working Group \\ Collaboration
}

\begin{abstract}
Additional material is published online only. To view please visit the journal online (http://dx.doi.org/10.1136/ rapm-2020-101479).
\end{abstract}

1 Department of Cardiovascular Sciences and Department of Anesthesiology, University Hospitals of the KU Leuven, Leuven, Belgium

2Department of Anaesthesia, University Hospital of Lausanne and University of Lausanne, Lausanne, Switzerland ${ }^{3}$ Department of Anaesthesia, Guy's and St Thomas' NHS Foundation Trust, King's College London, London, United Kingdom

${ }^{4}$ Department of Anesthesiology and Intensive Care, University Hospital of Örebro, Örebro, Sweden

${ }^{5}$ Department of Anesthesiology and Pain Management, University of Texas Southwestern Medical Center, Dallas, United States

Correspondence to Dr Eric Albrecht, Department of Anaesthesia, University Hospital of Lausanne, Lausanne BH 05.311, Switzerland; eric.albrecht@chuv.ch

KK-K and AP are co-primary authors.

Received 20 March 2020 Revised 18 May 2020

Accepted 24 May 2020 Published Online First 28 June 2020

\section{Check for updates}

(C) American Society of Regional Anesthesia \& Pain Medicine 2020. Re-use permitted under CC BY-NC. No commercial re-use. Published by BMJ.

\section{To cite: Korwin-} Kochanowska K, Potié A

El-Boghdadly K, et al. Reg Anesth Pain Med 2020:45:702-708

\section{ABSTRACT}

Hallux valgus repair is associated with moderate-tosevere postoperative pain. The aim of this systematic review was to assess the available literature and develop recommendations for optimal pain management after hallux valgus repair. A systematic review using PROcedure SPECific Postoperative Pain ManagemenT (PROSPECT) methodology was undertaken. Randomized controlled trials (RCTs) published in the English language from inception of database to December 2019 assessing postoperative pain using analgesic, anesthetic, and surgical interventions were identified from MEDLINE, EMBASE, and Cochrane Database, among others. Of the 836 RCTs identified, 55 RCTs and 1 systematic review met our inclusion criteria. Interventions that improved postoperative pain relief included paracetamol and nonsteroidal anti-inflammatory drugs or cyclo-oxygenase-2 selective inhibitors, systemic steroids, ankle block, and local anesthetic wound infiltration. Insufficient evidence was found for the use of gabapentinoids or wound infiltration with extended release bupivacaine or dexamethasone. Conflicting evidence was found for percutaneous chevron osteotomy. No evidence was found for homeopathic preparation, continuous local anesthetic wound infusion, clonidine and fentanyl as sciatic perineural adjuncts, bioabsorbable magnesium screws, and plaster slippers. No studies of sciatic nerve block met the inclusion criteria for PROSPECT methodology due to a wider scope of included surgical procedures or the lack of a control (no block) group. The analgesic regimen for hallux valgus repair should include, in the absence of contraindication, paracetamol and a non-steroidal anti-inflammatory drug or cyclo-oxygenase-2 selective inhibitor administered preoperatively or intraoperatively and continued postoperatively, along with systemic steroids, and postoperative opioids for rescue analgesia.

\section{INTRODUCTION}

Hallux valgus is a common forefoot deformity characterized by a medial prominence of the first metatarsus head and a valgus deviation of the first toe, with a prevalence of up to $33 \%$ in the general population. ${ }^{1}$ Hallux valgus repair is a frequent orthopedic surgery performed in industrialized countries, with estimates of more than 200000 people operated in the USA every year. ${ }^{1}$ Pain after hallux valgus repair has been reported to be

\section{Key messages}

Recommendations

- Systemic analgesia should include paracetamol and a non-steroidal anti-inflammatory drug or cyclo-oxygenase-2 selective inhibitor administered preoperatively or intraoperatively and continued postoperatively.

- Systemic steroids are recommended for their ability to provide postoperative analgesia.

- Ankle block is recommended as the first-option regional analgesic technique; wound infiltration with local anesthetic constitutes a reasonable alternative.

- Opioids should be reserved as rescue analgesics in the postoperative period.

Why was this guideline developed?

- Hallux valgus repair is associated with moderate-to-severe postoperative pain which may influence recovery.

- The aim of this guideline is to provide clinicians with robust evidence for optimal pain management after hallux valgus repair.

What other guidelines are available on this topic?

- There are no previously published formal guidelines specifically for pain management after hallux valgus repair, although there is one systematic review assessing analgesic interventions after foot and ankle surgery.

moderate to severe, with a median pain score of 5.1 out of $10 .^{2}$ A systematic review previously assessed the evidence for analgesic interventions following ankle and foot surgery for inpatients and outpatients, but was not specific to hallux valgus repair. ${ }^{3}$ As there is a substantial body of literature limited specifically to hallux valgus repair comparing many preoperative, intraoperative, and postoperative interventions to provide postoperative analgesia, a systematic review with an evidence-based approach is necessary to standardize interventions to reduce pain and improve patient comfort after hallux valgus repair specifically.

The PROSPECT (PROcedure SPECific Postoperative Pain ManagemenT) Working Group 
Key messages

How does this guideline differ from other guidelines?

- There are no previous guidelines; nevertheless, the PROSPECT (PROcedure SPECific Postoperative Pain ManagemenT) approach to developing guidelines is unique such that the available evidence is critically assessed for current clinical relevance, and the use of simple, non-opioid analgesics such as paracetamol and non-steroidal anti-inflammatory drugs or cyclo-oxygenase-2 selective inhibitor as basic analgesics is considered.

- This approach reports true clinical effectiveness by balancing the invasiveness of the analgesic interventions and the degree of pain after surgery, as well as balancing efficacy and adverse effects.

is a collaboration of anesthesiologists and surgeons working to formulate procedure-specific recommendations for pain management after common surgical procedures. The recommendations are based on procedure-specific literature review of randomized controlled trials (RCTs) and systematic reviews. A special feature of PROSPECT recommendations is that the methodology considers clinical practice, efficacy and adverse effects of analgesic techniques. ${ }^{4}$

The objective of this review was to systematically assess the available literature on pain management after hallux valgus repair. Postoperative pain outcomes (pain scores and analgesic requirements) were the primary outcomes. Other recovery outcomes, including adverse effects, were also evaluated, and the limitations of the data were reviewed. The ultimate aim was to develop recommendations for pain management after hallux valgus repair surgery.

\section{METHODS}

We adhered to previously described PROSPECT methodology in the conduct of this project. ${ }^{4}$ For this study, we specifically searched the following databases until December 14, 2019 for any RCTs: the US National Library of Medicine database (MEDLINE), the Excerpta Medica database (EMBASE), the Cochrane Database of Systematic Reviews, the Cochrane Central Register of Controlled Clinical Trials, Cumulative Index of Nursing and Allied Health Literature, PubMed, and Web of Science. The following were the search terms: hallux valgus repair OR hallux valgus OR hallux abductus OR hallux abductovalgus OR hallux valgus OR bunionectomy OR bunion OR metatarsophalangeal joint surgery, AND pain OR analgesi* OR anaesthe* OR vas OR visual analog* OR vrs OR epidural OR neuraxial OR intrathecal OR spinal OR caudal OR peripheral nerve OR peripheral block OR regional nerve OR infiltration OR instillation OR NSAID OR COX-2 OR paracetamol OR acetaminophen OR gabapentin OR pregabalin OR clonidine OR opioid OR ketamine OR corticosteroid OR dexamethasone OR patient controlled analgesia OR PCA. We completed this process by hand searching the reference lists of the included articles to identify any additional trials.

We excluded any article describing a phase II study for a drug that was unlicensed at the time of this review, and any study that compared different agents, dosages, concentrations, or analgesic techniques with no control group.

Quality assessment, data extraction, and data analysis adhered to the PROSPECT methodology. ${ }^{4}$ Pain intensity scores were used as the primary outcome measure. We defined a change of more than $10 \mathrm{~mm}$ on the visual analog scale or numerical rating score as clinically relevant. ${ }^{5}$ The effectiveness of each intervention for each outcome was evaluated by assessing the differences reported between treatment arms in each study. A meta-analysis was not performed due to heterogeneity in study design and result reporting, restricting pooled analysis. We also examined whether patients received basic analgesics, defined as the prescription of any non-opioid analgesics such as paracetamol and non-steroidal anti-inflammatory drugs or cyclo-oxygenase-2 selective inhibitor.

Recommendations were made according to PROSPECT methodology. ${ }^{4}$ In brief, this involved a grading of A-D according to the overall level of evidence, as determined by the quality of studies included, consistency of evidence, and study design. The proposed recommendations were sent to the PROSPECT Working Group for review and comments and a modified Delphi approach was used as previously described. Once a consensus was achieved, the lead authors drafted the final document, which was ultimately approved by the Working Group.

\section{RESULTS}

Among the 835 articles retrieved from the literature search and 1 article from bibliography screenings, $55 \mathrm{RCTs}^{6-60}$ and 1 systematic review ${ }^{61}$ were finally included (figure 1 ). The methodological quality assessments of the 55 RCT studies included for final qualitative analysis are summarized in online supplementary table S1. The characteristics of the included studies are shown in online supplementary tables S2 and S3. Online supplementary table $\mathrm{S} 4$ lists the articles excluded and the reasons for exclusion.

\section{Paracetamol, non-steroidal anti-inflammatory drugs, and cyclo-oxygenase-2 selective inhibitors}

One large study $(\mathrm{n}=323)$ administered intravenous propacetamol $2 \mathrm{~g}$ or oral paracetamol $1 \mathrm{~g}$ in the postanesthesia care unit and reported that both reduced pain scores within 6 postoperative hours when compared with placebo, without mentioning whether basic analgesics (ie, in this case non-steroidal antiinflammatory drugs) were prescribed or not; propacetamol was superior to paracetamol within 4 postoperative hours. ${ }^{31}$

A total of 12 studies examined the analgesic efficacy of nonsteroidal anti-inflammatory drugs or cyclo-oxygenase- 2 selective inhibitors. $^{7-9} 181922232629435759$ Three trials administered celecoxib $400 \mathrm{mg}$ daily and showed a reduction in pain scores on postoperative day (POD) $0^{7}$ or within the first 48 postoperative hours ${ }^{26}$ and a reduction in opioid consumption on POD1 and POD2 $2^{9}$ or only on POD2 ${ }^{26}$ after including $187,,^{7} 212,{ }^{9}$ and 212 patients. ${ }^{26}$ After prescribing diclofenac $100 \mathrm{mg}$ for 48 hours, pain scores and opioid consumption were consistently reduced during the study period in four large trials $\left(\mathrm{n}=200^{18}\right.$; $\mathrm{n}=389^{19} ; \mathrm{n}=201^{43} ; \mathrm{n}=376^{59}$ ), while another one including 187 patients reported no difference for both outcomes. ${ }^{22}$ Two trials investigated intravenous parecoxib $20 \mathrm{mg}$ or $40 \mathrm{mg}$ daily with the first dose administered 45 min preoperatively $(n=50)^{23}$ or 8 hours postoperatively $(n=376)^{8}$ and demonstrated a reduction in pain scores within 24 postoperative hours ${ }^{823}$ and a reduction in opioid consumption on POD1 and POD $2^{8}$ without an apparent dose-response effect. One trial $(n=59)$ showed a reduction in pain scores with meloxicam $30 \mathrm{mg}$ or $60 \mathrm{mg}$ during the first 48 postoperative hours without having any impact on opioid consumption and without an apparent dose-response effect. ${ }^{29}$ Finally, one trial $(n=89)$ assessing pregabalin $300 \mathrm{mg}$ or naproxen $550 \mathrm{mg}$ versus placebo showed a reduction in pain scores on POD1 in the pregabalin group, on POD1 and POD2 in 


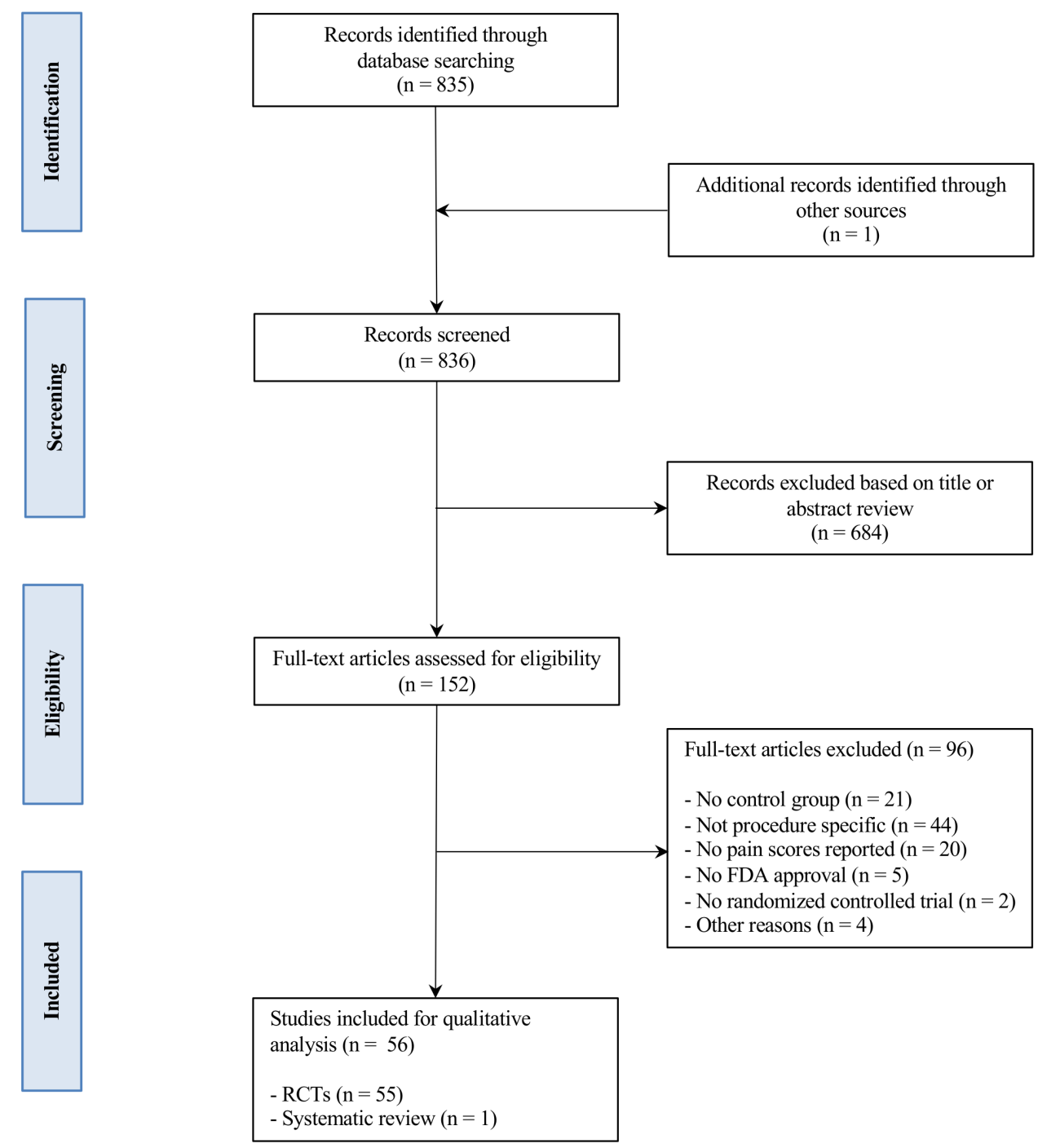

Figure 1 PRISMA flow diagram of studies. FDA, Food and Drug Administration; PRISMA, Preferred Reporting Items for Systematic Reviews and Meta-Analyses; RCT, randomized controlled trial.

the naproxen group, and a reduction in opioid consumption on POD1 and POD2 in both active groups. ${ }^{57}$ Among these studies, two did not prescribe basic analgesics (ie, in this case, paracetamol). ${ }^{2329}$

One trial of 276 patients showed that the combination of ibuprofen and paracetamol reduced pain scores and opioid consumption during the first 48 postoperative hours when compared with placebo, ibuprofen, or paracetamol. ${ }^{20}$

\section{Steroids}

Two trials compared the administration of steroids with placebo. ${ }^{640}$ In one study $(n=78)$, the intervention group received intramuscular betamethasone $12 \mathrm{mg} 30 \mathrm{~min}$ before the surgery, ${ }^{6}$ and in the other $(n=60)$ oral dexamethasone $9 \mathrm{mg} 60 \mathrm{~min}$ before and 24 hours after the surgery. ${ }^{40}$ Pain scores in the intervention groups were reduced on POD0 in both studies. ${ }^{640}$ One of these studies reported reduced pain scores on POD1 and cumulative opioid consumption during the first 3 postoperative days. ${ }^{40}$ Of note, paracetamol was administered in these studies.

\section{Systemic opioids}

Eleven studies assessed the analgesic efficacy of opioids when administered postoperatively. ${ }^{14} 1617384749-51$ 53-55 During the course of the study period, pain scores were consistently reduced with intravenous morphine $4 \mathrm{mg},{ }^{53} 54$ intravenous morphine $7.5 \mathrm{mg},{ }^{51}$ oral morphine $15 \mathrm{mg},{ }^{51}$ oral morphine $30 \mathrm{mg},{ }^{55}$ oral morphine $60 \mathrm{mg},{ }^{47}$ oxycodone $10 \mathrm{mg},{ }^{16} 50$ oxycodone $15 \mathrm{mg},{ }^{16}$ tapentadol $50 \mathrm{mg},{ }^{14} 16173850$ tapentadol $75 \mathrm{mg},{ }^{14} 161755$ tapentadol $100 \mathrm{mg},{ }^{17} 50$ or with tablets of paracetamol $325 \mathrm{mg} /$ hydrocodone $7.5 \mathrm{mg} .{ }^{49}$ Three out of these 11 studies did not prescribe basic analgesics. 145153

\section{Regional analgesic techniques}

Two studies examined the analgesic efficacy of an ankle block in addition to general anesthesia. ${ }^{35}$. After including 65 patients, Kir and $\mathrm{Kir}^{35}$ concluded that patients with an ankle block had reduced pain scores on POD1 and up to 12 postoperative months, when compared with a control group. Su and colleagues $^{52}$ randomly allocated 90 patients into three groups and showed that reported pain scores at 6 postoperative hours and opioid consumption at 6 and 12 postoperative hours were reduced in the ankle block group when compared with wound infiltration of local anesthetics or a control group. In the same study, patients in the wound infiltration group consumed less opioids at 24 postoperative hours when compared with the control group. ${ }^{52}$ 
No studies of sciatic block met the inclusion criteria for PROSPECT methodology due to a wider scope of included surgical procedures or the lack of a control (no block) group (see the Discussion section).

Regarding perineural adjuncts, the combination of clonidine $(n=30)^{13}$ or fentanyl $(n=30)^{39}$ with ropivacaine $0.75 \%$ for a combined sciatic and femoral nerve block did not reduce pain scores $^{13} 39$ or opioid consumption ${ }^{13}$ in the postoperative period. The mean time to first analgesic request was, however, increased from 13.7 to 16.8 hours with clonidine $(p=0.04) .^{13}$

All these studies included basic analgesics. ${ }^{13} 353952$

\section{Wound infiltration}

Six studies compared a wound infiltration technique with a control group, ${ }^{15} 15303456$ where all studies included basic analgesics, except one. ${ }^{15}$ In five studies, the authors compared wound infiltration with normal saline with bupivacaine (two studies: $\mathrm{n}=34^{30}$ and $\mathrm{n}=251^{56}$ ), with a mixture of ropivacaine with morphine, ketorolac, and epinephrine $(n=60),{ }^{34}$ with extended release (liposomal) bupivacaine $(n=193),{ }^{28}$ or with dexamethasone alone $(n=51) .{ }^{15}$ In all five studies the active medication group showed a reduction of pain scores in the first 24 postoperative hours, ${ }^{1528303456}$ and up to POD2 ${ }^{30}$ or even POD7. ${ }^{15}$ Finally, Braito et al ${ }^{12}$ did not show any significant difference in 42 patients when running a continuous infusion of ropivacaine $0.2 \%$ at a rate of $2 \mathrm{~mL} /$ hour for 24 hours through a wound catheter, without initial bolus.

\section{Surgical technique}

Fourteen studies investigated different surgical techniques, such as scarf osteotomy, chevron osteotomy, Hohmann procedure, or Lapidus procedure. $1011212425273233363744-4658$ None was associated with a reduction in pain scores, except one $(n=50)$ that showed a reduction on POD1 to postoperative week 6 , without difference at 6 postoperative months, in favor of percutaneous chevron/Akin osteotomy when compared with an open scarf/ Akin osteotomy. ${ }^{37}$ In contrast, Kaufmann et $a l^{33}(\mathrm{n}=47)$ investigated a percutaneous approach versus an open chevron osteotomy, but did not find any difference. Of note, 2 out of these 14 trials $(n=96$ and $n=55)$ specifically compared a scarf versus a chevron osteotomy and did not find any difference in postoperative pain scores. $^{2132}$

A systematic review of hallux valgus surgery including 25 studies concluded that the clinical impact of the different surgical procedures on the clinical outcomes, such as gait measurement, quality of life, and patient satisfaction, was negligible. ${ }^{61}$ They also specified that surgery is more effective than conservative treatment or no treatment in reducing pain in the first year following surgery. ${ }^{61}$

Two trials ( $n=26$ in both) compared the type of material used for the screws (bioabsorbable magnesium vs standard titanium) and did not find any difference in pain scores. ${ }^{42} 60$

None of the aforementioned RCTs reported whether basic analgesics were prescribed or not.

\section{Other modalities}

Meek and Anderson ${ }^{41}$ compared a plaster slipper versus crepe bandage $(n=27)$ for management of postoperative immobilization but did not find any significant difference in analgesic outcomes; use of basic analgesics was not described.

One study $(n=79)$ examined the analgesic effect of a homeopathic preparation (Traumeel S) administered for 14 consecutive days in the postoperative period on top of basic analgesics and
Box 1 Overall recommendations for pain management in patients undergoing hallux valgus repair.

Preoperative and intraoperative.

- Paracetamol (grade D).

- Cyclo-oxygenase-2 selective inhibitor or non-steroidal antiinflammatory drugs (grade A).

- Systemic steroids (grade A).

- Ankle block (grade A) or wound infiltration with single administration of local anesthetics (grade A). Ankle block recommended as a first choice and wound infiltration as an alternative (grade D).

Postoperative.

- Paracetamol (grade A).

- Cyclo-oxygenase-2 selective inhibitor or non-steroidal antiinflammatory drugs (grade A).

- Opioid for rescue (grade D).

Noteworthy, the literature on sciatic nerve block did not meet the inclusion requirements for PROSPECT methodology. PROSPECT, PROcedure SPECific Postoperative Pain ManagemenT.

showed no difference in pain scores for the study period, except on the day of surgery. ${ }^{48}$

\section{DISCUSSION}

Following the PROSPECT approach and based on available evidence, recommendations for analgesia following hallux valgus repair include paracetamol and non-steroidal anti-inflammatory drugs or cyclo-oxygenase-2 selective inhibitors, started preoperatively or intraoperatively and continued in the postoperative period, along with systemic steroids administered preoperatively or just before surgery, but only in the absence of contraindications (box 1). An ankle block should be the preferred analgesic technique, while wound infiltration with local anesthetic constitutes a reasonable alternative (box 1). Of note, continuous local anesthetic wound infusion without a preliminary bolus does not provide postoperative analgesia and is therefore not recommended. With concerns of opioid-related adverse effects such as postoperative nausea and vomiting ${ }^{62}$ and the contribution to the current opioid crisis, ${ }^{63}$ opioids should only be considered as rescue analgesics, if the above recommended approaches are not adequate (box 1).

Although there is limited procedure-specific evidence for paracetamol, as only one trial investigated the analgesic efficacy of this medication for hallux valgus specifically, the methodology was robust, with more than 300 patients included. ${ }^{31}$ Also, the PROSPECT methodology considers paracetamol as basic analgesic because it is well tolerated without significant side effects and has a favorable risk-benefit profile. ${ }^{4}$

Regarding systemic steroids, although the studies used intramuscular betamethasone and oral dexamethasone, the effects of these drugs are systemic. We recommend intravenous dexamethasone because it is recommended for postoperative nausea and vomiting prophylaxis. ${ }^{64}$ Moreover, intravenous dexamethasone enhances the impact of a regional analgesic technique such as ankle block or anesthetic infiltration. ${ }^{65}$

To date, only two trials have investigated the benefit of an ankle block for this surgery specifically, but they both showed an important effect size. ${ }^{35} 52$ Additionally, two trials published more than 15 years ago concluded that an anatomical landmark ankle block combined with general anesthesia reduced pain scores ${ }^{66}$ 
or increased the time to first pain after forefoot surgery, ${ }^{67}$ when compared with general anesthesia alone. Despite the publication of a single trial showing the superiority of the ankle block over wound infiltration of local anesthetics, ${ }^{52}$ ankle block should be favored as it may allow the surgery to be performed without additional general or spinal anesthesia. ${ }^{68}$ Moreover, it also reduces the anesthesia-related time in the operating theater, especially if the regional procedure is performed prior to operating room entry. ${ }^{68}$

Hallux valgus repair can also be performed under a combined saphenous and popliteal sciatic nerve blocks, but no trial specifically investigated this approach with a control group. Noteworthy, one trial compared a sciatic nerve block with another regional technique, a mid-foot block, both combined with sedation; the authors concluded that both techniques provided similar postoperative analgesia after hallux valgus repair, although ambulation was delayed in the sciatic nerve block group. ${ }^{69}$ McLeod and colleagues $^{70}$ compared sciatic nerve block with wound infiltration and also found similar postoperative analgesia in both groups when patients had foot surgery under general anesthesia. Finally, a trial published more than 25 years ago showed that sciatic nerve block and ankle block performed with anatomical landmarks after forefoot surgery under general anesthesia resulted in comparable postoperative pain control. ${ }^{71}$ Of note, these last two studies showed significantly longer analgesia with sciatic nerve block compared with wound infiltration ${ }^{70}$ or ankle block ${ }^{71}$ with the same solution ( $0.5 \%$ bupivacaine). Notwithstanding, additional research is needed to properly compare a sciatic nerve block with an ankle block under ultrasound guidance in a contemporary practice. Many trials compared different injection techniques or different concentrations of local anesthetic for sciatic nerve block. But according to our methodology, we do not elaborate recommendations on these items because no comparison is performed against a control group. That said, combining fentanyl or clonidine with local anesthetics for a combined femoral and sciatic nerve block does not reduce pain scores or opioid consumption but prolongs time to first analgesic request in the postoperative period. When considering a sciatic nerve block for an outpatient procedure, the patient's recovery plan and weightbearing status should be considered. For patients whose surgeons do not restrict weightbearing postoperatively, an ankle block avoids foot drop from sciatic nerve block, which may improve safety at home.

Insufficient evidence was found for the use of gabapentinoids, or for wound infiltration with extended release bupivacaine or dexamethasone, as the analgesic benefits were only demonstrated by a single trial each (table 1). Consequently, future studies are required to confirm the preliminary results of these interventions. Additionally, studies exploring the potential reduction in pain scores beyond the first 24 postoperative hours with extended release bupivacaine for ankle block, along with the optimal technique of injection, would be valuable, although not approved for this indication by the Food and Drug Administration.

Finally, interventions that are not recommended were percutaneous chevron osteotomy due to conflicting evidence, and homeopathic preparation (Traumeel), bioabsorbable magnesium screws, and plaster slipper for immobilization due to lack of evidence (table 1).

The limitations in this review are related to those of the included studies. There was considerable heterogeneity between studies with regard to dosing regimens and route of administration, as well as timing of pain assessments. The small size of many studies has the potential for estimation effect and does not provide safety profile of the analgesic interventions. In a majority of the studies the analgesic intervention was not evaluated against an optimized multimodal analgesic regimen.
Table 1 Analgesic interventions that are not recommended for pain management in patients undergoing hallux valgus repair

\begin{tabular}{|c|c|}
\hline Intervention & Reason for not recommending \\
\hline \multicolumn{2}{|l|}{ Preoperative } \\
\hline Pregabalin. & Limited procedure-specific evidence. \\
\hline $\begin{array}{l}\text { Clonidine as perineural adjunct for a combined } \\
\text { femoral and sciatic nerve block. }\end{array}$ & Lack of procedure-specific evidence. \\
\hline $\begin{array}{l}\text { Fentanyl as perineural adjunct for a combined } \\
\text { femoral and sciatic nerve block. }\end{array}$ & Lack of procedure-specific evidence. \\
\hline \multicolumn{2}{|l|}{ Intraoperative } \\
\hline $\begin{array}{l}\text { Wound infiltration with extended release } \\
\text { bupivacaine. }\end{array}$ & Limited procedure-specific evidence. \\
\hline Wound infiltration with dexamethasone. & Limited procedure-specific evidence. \\
\hline $\begin{array}{l}\text { Continuous wound infiltration with local } \\
\text { anesthetics. }\end{array}$ & Lack of procedure-specific evidence. \\
\hline \multicolumn{2}{|l|}{ Postoperative } \\
\hline Plaster slipper vs crepe bandage. & Lack of procedure-specific evidence. \\
\hline Homeopathic Traumeel. & Lack of procedure-specific evidence. \\
\hline \multicolumn{2}{|l|}{ Surgical technique } \\
\hline Percutaneous chevron osteotomy. & $\begin{array}{l}\text { Conflicting procedure-specific } \\
\text { evidence. }\end{array}$ \\
\hline Bioabsorbable magnesium screws. & Lack of procedure-specific evidence. \\
\hline
\end{tabular}

Indeed, in many of the trials, the patients did not receive basic analgesics inclusive of paracetamol or non-steroidal antiinflammatory drugs. Moreover, pain scores were reported in many trials with unusual metrics, such as summed pain intensity differences through 24 hours; time-weighted sum of total pain relief through 24 hours; time-adjusted sum of pain intensity differences over 48 hours; or total pain relief over 8 hours. Finally, the recommendation on ankle block is based on just two studies and blocks were combined with general anesthesia.

\section{CONCLUSIONS}

In summary, this review has identified that analgesic regimen for hallux valgus repair should include, in the absence of contraindications, paracetamol and a non-steroidal antiinflammatory drug or cyclo-oxygenase- 2 selective inhibitor administered preoperatively or intraoperatively and continued postoperatively, along with systemic steroids, and postoperative opioids for rescue analgesia. As a regional technique, ankle block should be preferred, while wound infiltration with local anesthetic constitutes a reasonable alternative. There is insufficient evidence to recommend gabapentinoids or wound infiltration with extended release bupivacaine after hallux valgus repair.

\section{Twitter Kariem El-Boghdadly @elboghdadly and Eric Albrecht @DrEAlbrecht}

Collaborators PROSPECT Working Group: GP Joshi, E Pogatzki-Zahn, M Van de Velde, S Schug, H Kehlet, F Bonnet, N Rawal, A Delbos, P Lavand'homme, H Beloeil, J Raeder, A Sauter, E Albrecht, P Lirk, S Freys, and D Lobo.

Contributors KK-K and KE-B conducted the literature search. KK-K, KE-B, AP, and $E A$ analyzed the retrieved articles. $K E-B, G J, N R$, and $E A$ wrote the manuscript, which was reviewed and edited by all the other authors, who have also participated in the PROSPECT Working Group meetings using the Delphi method and in defining the methodology of the PROSPECT group.

Funding PROSPECT is supported by an unrestricted grant from the European Society of Regional Anaesthesia and Pain Therapy (ESRA).

Competing interests EA is Associate Editor of the Regional Anesthesia \& Pain Medicine and has received grants from the Swiss Academy for Anaesthesia Research (SACAR), Lausanne, Switzerland (50 000 CHF; no grant number attributed), from B Braun Medical (56 100 CHF; no grant number attributed), and from the Swiss National Science Foundation to support his clinical research (353 408 CHF; grant number: 32003B_169974/1). EA has also received honoraria from B Braun Medical 
and Sintetica UK. KE-B is Editor of Anaesthesia and has received educational, research, or consulting funding from Ambu, Fisher \& Paykel Healthcare, and GE Healthcare. NR has received honoraria from Sintetica and Baxter. GJ has received honoraria from Baxter and Pacira Pharmaceuticals. In the past, PROSPECT has received unrestricted grants from Pfizer, New York, New York, USA, and Grunenthal, Aachen, Germany. MVdV has received honoraria from Sintetica, Grunenthal, Vifor Pharma, MSD, Nordic Pharma, Janssen Pharmaceuticals, Heron Therapeutics, CSL Behring, and Aquettant. EP-Z has received honoraria from Mundipharma, Grunenthal, MSD, Janssen-Cilag, Fresenius Kabi, and AcelRx.

Patient consent for publication Not required.

Provenance and peer review Not commissioned; externally peer reviewed.

Data availability statement Data are available upon reasonable request. Data will be available upon an email sent to the corresponding author.

Open access This is an open access article distributed in accordance with the Creative Commons Attribution Non Commercial (CC BY-NC 4.0) license, which permits others to distribute, remix, adapt, build upon this work non-commercially, and license their derivative works on different terms, provided the original work is properly cited, an indication of whether changes were made, and the use is noncommercial. See: http://creativecommons.org/licenses/by-nc/4.0/.

\section{ORCID iDs}

Kariem El-Boghdadly http://orcid.org/0000-0002-9912-717X

Eric Albrecht http://orcid.org/0000-0001-6432-1311

\section{REFERENCES}

1 Torkki M, Malmivaara A, Seitsalo S, et al. Surgery vs orthosis vs watchful waiting for hallux valgus: a randomized controlled trial. JAMA 2001;285:2474-80.

2 Gerbershagen HJ, Aduckathil S, van Wijck AJM, et al. Pain intensity on the first day after surgery: a prospective cohort study comparing 179 surgical procedures. Anesthesiology 2013;118:934-44.

3 Wang J, Liu GT, Mayo HG, et al. Pain management for elective foot and ankle surgery: a systematic review of randomized controlled trials. J Foot Ankle Surg 2015:54:625-35.

4 Joshi GP, Van de Velde M, Kehlet H, et al. Development of evidence-based recommendations for procedure-specific pain management: prospect methodology. Anaesthesia 2019;74:1298-304.

5 Myles PS, Myles DB, Galagher W, et al. Measuring acute postoperative pain using the visual analog scale: the minimal clinically important difference and patient acceptable symptom state. Br J Anaesth 2017;118:424-9.

6 Aasboe V, Raeder JC, Groegaard B. Betamethasone reduces postoperative pain and nausea after ambulatory surgery. Anesth Analg 1998;87:319-23.

7 Altman R, Daniels S, Young CL. Indomethacin submicron particle capsules provide effective pain relief in patients with acute pain: a phase 3 study. Phys Sportsmed 2013:41:7-15.

8 Apfelbaum JL, Desjardins PJ, Brown MT, et al. Multiple-day efficacy of parecoxib sodium treatment in postoperative bunionectomy pain. Clin J Pain 2008;24:784-92.

9 Argoff C, McCarberg B, Gudin J, et al. SoluMatrix ${ }^{\circ}$ diclofenac: sustained OpioidSparing effects in a phase 3 study in patients with postoperative pain. Pain Med 2016:17:1933-41.

10 Avcu B, Akalin Y, Cevik N, et al. Scarf osteotomy or mau osteotomy for correction of moderate to severe hallux valgus deformity: a prospective, randomized study. Europ Res J 2018:4:6-15.

11 Baumhauer JF, Singh D, Glazebrook M, et al. Prospective, randomized, multi-centered clinical trial assessing safety and efficacy of a synthetic cartilage implant versus first metatarsophalangeal arthrodesis in advanced hallux rigidus. Foot Ankle Int 2016:37:457-69.

12 Braito M, Dammerer D, Schlager $A$, et al. Continuous wound infiltration after hallux valgus surgery. Foot Ankle Int 2018;39:180-8.

13 Casati A, Magistris L, Fanelli G, et al. Small-dose clonidine prolongs postoperative analgesia after sciatic-femoral nerve block with $0.75 \%$ ropivacaine for foot surgery. Anesth Analg 2000;91:388-92.

14 Chen Y-J, Chiang C-C, Huang P-J, et al. Tapentadol immediate-release for acute postbunionectomy pain: a phase 3, randomized, double-blind, placebo-controlled, parallel-group study in Taiwan. Curr Med Res Opin 2015;31:2001-9.

15 Curda GA. Postoperative analgesic effects of dexamethasone sodium phosphate in bunion surgery. J Foot Surg 1983;22:187-91.

16 Daniels S, Casson E, Stegmann J-U, et al. A randomized, double-blind, placebocontrolled phase 3 study of the relative efficacy and tolerability of tapentadol IR and oxycodone IR for acute pain. Curr Med Res Opin 2009;25:1551-61.

17 Daniels SE, Upmalis D, Okamoto A, et al. A randomized, double-blind, phase III study comparing multiple doses of tapentadol IR, oxycodone IR, and placebo for postoperative (bunionectomy) pain. Curr Med Res Opin 2009;25:765-76.

18 Daniels SE, Baum DR, Clark F, et al. Diclofenac potassium liquid-filled soft gelatin capsules for the treatment of postbunionectomy pain. Curr Med Res Opin 2010;26:2375-84
19 Daniels SE, Riff D, Diamond E, et al. An assessment of the efficacy and safety of diclofenac potassium liquid-filled capsules in patients with various levels of baseline pain intensity. Curr Med Res Opin 2012;28:953-61.

20 Daniels SE, Playne R, Stanescu I, et al. Efficacy and safety of an intravenous acetaminophen/ibuprofen fixed-dose combination after bunionectomy: a randomized double-blind, factorial, placebo-controlled trial. Clin Ther 2019;41:1982-95.

21 Deenik AR, Pilot P, Brandt SE, et al. Scarf versus chevron osteotomy in hallux valgus: a randomized controlled trial in 96 patients. Foot Ankle Int 2007;28:537-41.

22 Desjardins PJ, Black PM, Daniels $\mathrm{S}$, et al. A randomized controlled study comparing rofecoxib, diclofenac sodium, and placebo in post-bunionectomy pain. Curr Med Res Opin 2004;20:1523-37.

23 Desjardins PJ, Traylor L, Hubbard RC. Analgesic efficacy of preoperative parecoxib sodium in an orthopedic pain model. J Am Podiatr Med Assoc 2004;94:305-14.

24 Faber FWM, Mulder PGH, Verhaar JAN. Role of first ray hypermobility in the outcome of the Hohmann and the Lapidus procedure. A prospective, randomized trial involving one hundred and one feet. J Bone Joint Surg Am 2004;86:486-95.

25 Faber FWM, van Kampen PM, Bloembergen MW. Long-Term results of the Hohmann and Lapidus procedure for the correction of hallux valgus: a prospective, randomised trial with eight- to 11-year follow-up involving 101 feet. Bone Joint J 2013;95B:1222-6

26 Gibofsky A, Altman RD, Young C, et al. Lower-dose indomethacin submicron particle capsules' combined safety from two phase 3 studies in patients with acute pain following elective surgery. Arthritis Rheum 2013;65:S873.

27 Glazebrook M, Copithorne P, Boyd G, et al. Proximal opening wedge osteotomy with wedge-plate fixation compared with proximal chevron osteotomy for the treatment of hallux valgus: a prospective, randomized study. J Bone Joint Surg Am 2014;96:1585-92.

28 Golf M, Daniels SE, Onel E. A phase 3, randomized, placebo-controlled trial of DepoFoam $®$ bupivacaine (extended-release bupivacaine local analgesic) in bunionectomy. Adv Ther 2011;28:776-88.

29 Gottlieb IJ, Tunick DR, Mack RJ, et al. Evaluation of the safety and efficacy of an intravenous nanocrystal formulation of meloxicam in the management of moderateto-severe pain after bunionectomy. J Pain Res 2018;11:383-93.

30 Haddon J, Finsen V. Poor analgesic effect of instilling local anaesthetic during surgery for hallux valgus. A randomised, double blind trial. Foot 2003;13:136-9.

31 Jarde 0, Boccard E. Parenteral versus oral route increases paracetamol efficacy. Clin Drug Investig 1997;14:474-81.

32 Jeuken RM, Schotanus MGM, Kort NP, et al. Long-Term follow-up of a randomized controlled trial comparing Scarf to chevron osteotomy in hallux valgus correction. Foot Ankle Int 2016;37:687-95.

33 Kaufmann G, Dammerer D, Heyenbrock F, et al. Minimally invasive versus open chevron osteotomy for hallux valgus correction: a randomized controlled trial. Int Orthop 2019:43:343-50.

$34 \mathrm{Kim}$ BS, Shim DS, Lee JW, et al. Comparison of multi-drug injection versus placebo after hallux valgus surgery. Foot Ankle Int 2011;32:856-60.

35 Kir MC, Kir G. Ankle nerve block adjuvant to general anesthesia reduces postsurgical pain and improves functional outcomes in hallux valgus surgery. Med Princ Pract 2018;27:236-40

36 Lechler P, Feldmann C, Köck FX, et al. Clinical outcome after Chevron-Akin double osteotomy versus isolated chevron procedure: a prospective matched group analysis. Arch Orthop Trauma Surg 2012;132:9-13.

37 Lee M, Walsh J, Smith MM, et al. Hallux valgus correction comparing percutaneous Chevron/Akin (PECA) and open Scarf/Akin osteotomies. Foot Ankle Int 2017:38:838-46.

38 Lee YK, Ko JS, Rhim HY, et al. Acute postoperative pain relief with immediate-release tapentadol: randomized, double-blind, placebo-controlled study conducted in South Korea. Curr Med Res Opin 2014:30:2561-70.

39 Magistris L, Casati A, Albertin A, et al. Combined sciatic-femoral nerve block with $0.75 \%$ ropivacaine: effects of adding a systemically inactive dose of fentanyl. Eur J Anaesthesiol 2000;17:348-53.

40 Mattila K, Kontinen VK, Kalso E, et al. Dexamethasone decreases oxycodone consumption following osteotomy of the first metatarsal bone: a randomized controlled trial in day surgery. Acta Anaesthesio/ Scand 2010;54:268-76.

41 Meek R, Anderson EG. Plaster slipper versus crepe bandage after Wilson's osteotomy for hallux valgus. Foot 1999;9:138-41.

42 Plaass C, von Falck C, Ettinger S, et al. Bioabsorbable magnesium versus standard titanium compression screws for fixation of distal metatarsal osteotomies - 3 year results of a randomized clinical trial. J Orthop Sci 2018;23:321-7.

43 Riff DS, Duckor S, Gottlieb I, et al. Diclofenac potassium liquid-filled soft gelatin capsules in the management of patients with postbunionectomy pain: a phase III, multicenter, randomized, double-blind, placebo-controlled study conducted over 5 days. Clin Ther 2009;31:2072-85.

44 Şahin N, Cansabuncu G, Çevik N, et al. A randomized comparison of the proximal crescentic osteotomy and rotational Scarf osteotomy in the treatment of hallux valgus. Acta Orthop Traumatol Turc 2018:52:261-6.

45 Saro C, Andrén B, Wildemyr Z, et al. Outcome after distal metatarsal osteotomy for hallux valgus: a prospective randomized controlled trial of two methods. Foot Ankle Int 2007;28:778-87. 
46 Saro C, Andrén B, Felländer-Tsai L, et al. Plantar pressure distribution and pain after distal osteotomy for hallux valgus. A prospective study of 22 patients with 12-month follow-up. Foot 2007;17:84-93.

47 Scholz A, Bothmer J, Kok M, et al. Cebranopadol: a novel, first-in-class, strong analgesic: results from a randomized phase IIA clinical trial in postoperative acute pain. Pain Physician 2018;21:E193-206.

48 Singer SR, Amit-Kohn M, Weiss S, et al. Traumeel S for pain relief following hallux valgus surgery: a randomized controlled trial. BMC Clin Pharmacol 2010;10:9.

49 Singla N, Sisk L, Kostenbader K, et al. (415) time to onset of pain relief with biphasic immediate-release/extended-release oxycodone/acetaminophen in patients with acute postoperative pain: a randomized controlled trial. J Pain 2015;16:\$79.

50 Stegmann J-U, Weber H, Steup A, et al. The efficacy and tolerability of multiple-dose tapentadol immediate release for the relief of acute pain following orthopedic (bunionectomy) surgery. Curr Med Res Opin 2008;24:3185-96.

51 Stoker DG, Reber KR, Waltzman LS, et al. Analgesic efficacy and safety of morphinechitosan nasal solution in patients with moderate to severe pain following orthopedic surgery. Pain Med 2008;9:3-12.

52 Su M-P, Huang P-J, Tseng K-Y, et al. Pretreatment of ankle nerve block provides better postoperative analgesia than peri-incisional local anesthetic infiltration in hallux valgus correction surgery. Kaohsiung J Med Sci 2019;35:168-74.

53 Thipphawong JB, Babul N, Morishige RJ, et al. Analgesic efficacy of inhaled morphine in patients after bunionectomy surgery. Anesthesiology 2003;99:693-700.

54 Viscusi ER, Webster L, Kuss M, et al. A randomized, phase 2 study investigating TRV130, a biased ligand of the $\mu$-opioid receptor, for the intravenous treatment of acute pain. Pain 2016:157:264-72.

55 Viscusi ER, Allard R, Sohns M, et al. Tapentadol immediate release for moderate to severe acute post-surgery pain. J Opioid Manag 2019:15:51-67.

56 Viscusi E, Gimbel JS, Pollack RA, et al. HTX-011 reduced pain intensity and opioid consumption versus bupivacaine $\mathrm{HCl}$ in bunionectomy: phase III results from the randomized epoch 1 study. Reg Anesth Pain Med 2019;44:700-6.

57 Wang H, Gargano C, Lukac S, et al. An enhanced bunionectomy model as a potential tool for early decision-making in the development of new analgesics. Adv Ther 2010;27:963-80.

58 Wester JU, Hamborg-Petersen E, Herold N, et al. Open wedge metatarsal osteotomy versus crescentic osteotomy to correct severe hallux valgus deformity - A prospective comparative study. Foot Ankle Surg 2016;22:26-31.
59 Willens JS, Bucior I, Bujanover S, et al. Assessment of rescue opioid use in patients with post-bunionectomy pain treated with diclofenac potassium liquid-filled capsules. J Pain Res 2015;8:53-62.

60 Windhagen $\mathrm{H}$, Radtke $\mathrm{K}$, Weizbauer $\mathrm{A}$, et al. Biodegradable magnesium-based screw clinically equivalent to titanium screw in hallux valgus surgery: short term results of the first prospective, randomized, controlled clinical pilot study. Biomed Eng Online 2013; $12: 62$.

61 Klugarova J, Hood V, Bath-Hextall F, et al. Effectiveness of surgery for adults with hallux valgus deformity: a systematic review. JBI Database System Rev Implement Rep 2017; 15:1671-710.

62 Frauenknecht J, Kirkham KR, Jacot-Guillarmod A, et al. Analgesic impact of intraoperative opioids vs. opioid-free anaesthesia: a systematic review and meta-analysis. Anaesthesia 2019;74:651-62.

63 Soneji N, Clarke HA, Ko DT, et al. Risks of developing persistent opioid use after major surgery. JAMA Surg 2016;151:1083-4.

64 Gan TJ, Diemunsch P, Habib AS, et al. Consensus guidelines for the management of postoperative nausea and vomiting. Anesth Analg 2014;118:85-113.

65 Baeriswyl M, Kirkham KR, Jacot-Guillarmod A, et al. Efficacy of perineural vs systemic dexamethasone to prolong analgesia after peripheral nerve block: a systematic review and meta-analysis. Br J Anaesth 2017;119:183-91.

66 Needoff M, Radford P, Costigan P. Local anesthesia for postoperative pain relief after foot surgery: a prospective clinical trial. Foot Ankle Int 1995;16:11-13.

67 Clough TM, Sandher D, Bale RS, et al. The use of a local anesthetic foot block in patients undergoing outpatient bony forefoot surgery: a prospective randomized controlled trial. J Foot Ankle Surg 2003;42:24-9.

68 López AM, Sala-Blanch X, Magaldi M, et al. Ultrasound-Guided ankle block for forefoot surgery: the contribution of the saphenous nerve. Reg Anesth Pain Med 2012;37:554-7.

69 Adam F, Pelle-Lancien E, Bauer T, et al. Anesthesia and postoperative analgesia after percutaneous hallux valgus repair in ambulatory patients. Ann Fr Anesth Reanim 2012;31:e265-8.

70 McLeod DH, Wong DH, Claridge RJ, et al. Lateral popliteal sciatic nerve block compared with subcutaneous infiltration for analgesia following foot surgery. Can J Anaesth 1994;41:673-6.

71 McLeod DH, Wong DH, Vaghadia $\mathrm{H}$, et al. Lateral popliteal sciatic nerve block compared with ankle block for analgesia following foot surgery. Can J Anaesth 1995;42:765-9. 